\title{
Conductivity of microfibrillar polymer-polymer composites with CNT-loaded microfibrils or compatibilizer: A comparative study
}

\author{
S. M. Panamoottil ${ }^{1}$, P. Pötschke ${ }^{2}$, R. J. T. Lin ${ }^{1}$, D. Bhattacharyya ${ }^{1}$, S. Fakirov ${ }^{1 *}$ \\ ${ }^{1}$ The University of Auckland, Centre for Advanced Composite Materials, Department of Mechanical Engineering, Private \\ Bag 92019, 1142 Auckland, New Zealand \\ ${ }^{2}$ Leibniz Institute of Polymer Research Dresden, Department of Functional Nanocomposites and Blends, Hohe Str. 6, \\ 01069 Dresden, Germany
}

Received 18 January 2013; accepted in revised form 4 April 2013

\begin{abstract}
Conductive polymer composites have wide ranging applications, but when they are produced by conventional melt blending, high conductive filler loadings are normally required, hindering their processability and reducing mechanical properties. In this study, two types of polymer-polymer composites were studied: i) microfibrillar composites (MFC) of polypropylene (PP) and $5 \mathrm{wt} \%$ carbon nanotube (CNT) loaded poly(butylene terephthalate) (PBT) as reinforcement, and ii) maleic anhydride-grafted polypropylene (PP-g-MA) compatibilizer, loaded with $5 \mathrm{wt} \%$ CNTs introduced into an MFC of $\mathrm{PP}$ and poly(ethylene terephthalate) (PET) in concentrations of 5 and $10 \mathrm{wt} \%$. For the compatibilized composite type, PP and PET were melt-blended, cold-drawn and pelletized, followed by dry-mixing with PP-g-MA/CNT, re-extrusion at $200^{\circ} \mathrm{C}$, and cold-drawing. The drawn blends produced were compression moulded to produce sheets with MFC structure. Using scanning electron microscopy, CNTs coated with PP-g-MA could be observed at the interface between PP matrix and PET microfibrils in the compatibilized blends. The volume resistivities tested by four-point test method were: $2.87 \cdot 10^{8}$ and 9.93 $10^{7} \Omega \cdot \mathrm{cm}$ for the $66.5 / 28.5 / 5$ and $63 / 27 / 10$ (by wt $\%$ ) PP/PET/(PP-g-MA/CNT) blends, corresponding to total CNT loadings (in the composites) of $0.07 \mathrm{vol} \%(0.24 \mathrm{wt} \%)$ and $0.14 \mathrm{vol} \%(0.46 \mathrm{wt} \%)$, respectively. For the non-compatibilized MFC types based on PP/(PBT/CNT) with higher and lower melt flow grades of PP, the resistivities of $70 /(95 / 5)$ blends were $1.9 \cdot 10^{6}$ and $1.5 \cdot 10^{7} \Omega \cdot \mathrm{cm}$, respectively, corresponding to a total filler loading (in the composite) of $0.44 \mathrm{vol} \%(1.5 \mathrm{wt} \%)$ in both MFCs.
\end{abstract}

Keywords: polymer composites, electroconductivity, compatibilizer, polymer-polymer composites, carbon nanotubes

\section{Introduction}

An increasing amount of research over the last decade has been dedicated to studying and improving the properties of conducting polymer composites (CPCs). CPCs possess an interesting combination of properties including low weight, non-linear voltage-current behaviour, and environmental-sensitive resistivity, properties which could lead to applications in antistatic, electrostatic dissipative and electromagnetic shielding, as well as in sensors and related devices [1-4]. Anisotropic CPCs could even have applications in the semiconductor industry [5-7].

Conductive fillers have been dispersed in polymers using a variety of techniques, including melt mixing, in-situ polymerization, solution mixing, and applying the latex approach [8-10]. However, as far as commercial application is concerned, melt mixing is the most attractive technique. Early attempts for producing CPCs involved mixing conductive

\footnotetext{
${ }^{*}$ Corresponding author, e-mail: ohtsf@wmail.chem.uni-sofia.bg (C) BME-PT
} 
filler with a bulk polymer, and above a certain filler loading, called percolation threshold, the composite begins conducting. This approach, however, depending on the aspect ratio of the conducting filler, usually requires relatively high filler content to achieve conductivity, which is undesirable as far as processability, surface finish and cost are concerned [11]. Therefore, a selective localization of conductive fillers in one component or at the interface of twocomponent blends is a suitable method to reduce the filler amount needed for electrical percolation. This was shown especially for blends with co-continuous structure, where the conductive filler is localized in one of the components and depending on the component composition the percolation can occur at lower than the half amount of fillers as compared with the bulk filling [12]. For carbon black as filler even the case of interfacial localization was reported [13].

The creation of fibrillar polymer-polymer composites as a special case of polymer blends offers the opportunity to load only the blend matrix or the minor reinforcing component, or even only the interface layer between the matrix and the reinforcing fibrils. The described four cases of loading a polymer or a polymer blend having the structure of a fibrillar polymer-polymer composite with conductive fillers are schematically illustrated in Figure 1. Samples corresponding to case $b$ ) of Figure 1. (matrix loading) were not prepared in this study, instead, bulk-loaded samples (Figure 1a) were used as a model system because they are free from any interaction with the reinforcing fibrils.

With reduction of filler content in mind, it should be pointed out that the choice of conductive filler by itself can make a significant difference in the percolation threshold of a filled polymer or blend. Carbon black (CB) had been the conductive filler of choice [14-19] for many years, until the recent surge in application of carbon nanotubes (CNTs) [20-24], which, due to their high aspect ratio, achieve percolation at much lower contents than CB.

With lower filler content as the aim, CPCs based on polymer blends have been observed to achieve percolation at lower filler loadings than those based on a single polymer [12, 25-27]. This can be attributed to a mechanism called double-percolation [28-35] i.e., the filler is selectively localized in one of the blend components forming a conductive network. However, in most of these cases the two polymers have weak interfacial adhesion, resulting in poor mechanical properties of the blend. This can be improved to a certain extent by applying the concept of microfibrillar composites (MFCs) [36-39].

Microfibrillar composites are prepared from immiscible polymer blends, where the reinforcement is provided by fibrils of the minor component [37, 38]. Requirements to be met in the choice of blend components [39] include: i) both polymers should be amenable to a sufficient amount of drawing to produce microfibrils with high molecular orientation, ii) melting temperature of the minor component should be at least $40 \mathrm{~K}$ above that of the matrix polymer, in order to prevent melting of fibrils during consolidation, iii) both polymers should be processable at a single temperature without degrading, iv) blend composition should be selected in that way that the minor component forms a dispersed phase in the matrix. Once suitable blend partners are selected, the process sequence for MFC manufacture can be described simply as follows: i) meltblending of the polymers above melting of higher melting component, ii) cold-drawing (for fibrillation) of the blend above the glass transition temperature of the minor reinforcing component, iii) isotropization of the blend by processing above melt temperature of matrix, but below that of the reinforcing fibrils.

The MFC concept has been applied to polypropylene (PP) melt blended with nylon-6,6 (PA66) loaded with multiwalled carbon nanotubes (MWCNTs) and cold-drawn, followed by isotropization to form MFCs [40]. Observation under the scanning electron microscope (SEM) revealed good dispersion of MWCNTs in the PA66 microfibrils. The PA66 fibrils themselves were found to reinforce the matrix, while the MWCNTs seemed to have a detrimental effect on the mechanical properties. The experience gained from this study was helpful in selecting the material ratios and processing parameters used in the current study.

A significant amount of work related to MFC-based CPCs has been carried out previously [11, 17, 41-43]. Early studies dealt with MFCs of polyethylene (PE)/poly(ethylene terephthalate) (PET) with $\mathrm{CB}$ as a filler. Filler loadings as high as 5.9 vol\% were required to achieve percolation. These authors were later successful in finding out that the $\mathrm{CB}$ particles are selectively located in higher concentration near the PE/PET interface (without any special target- 


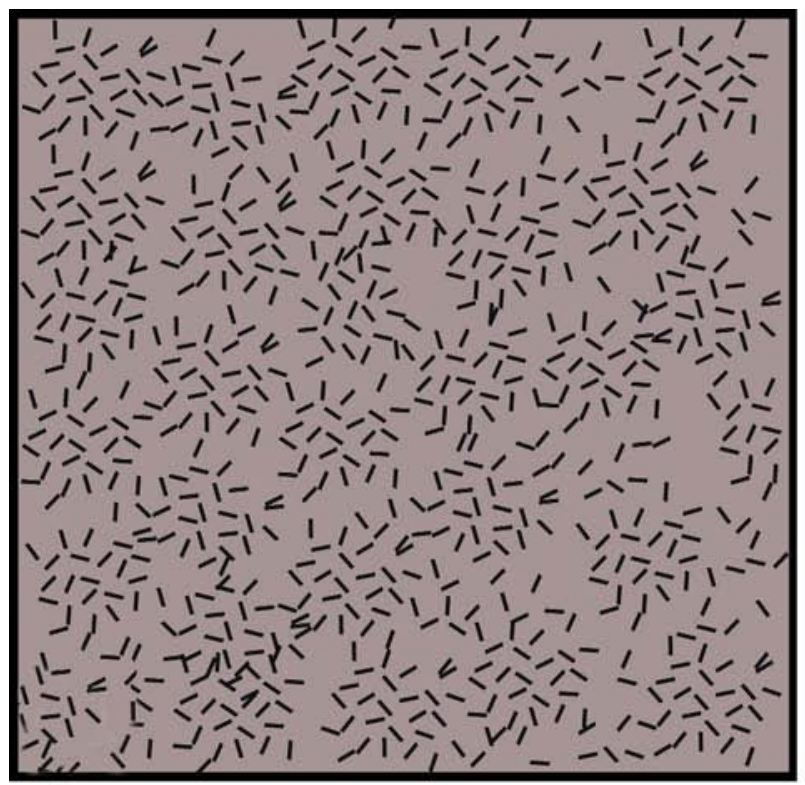

a)

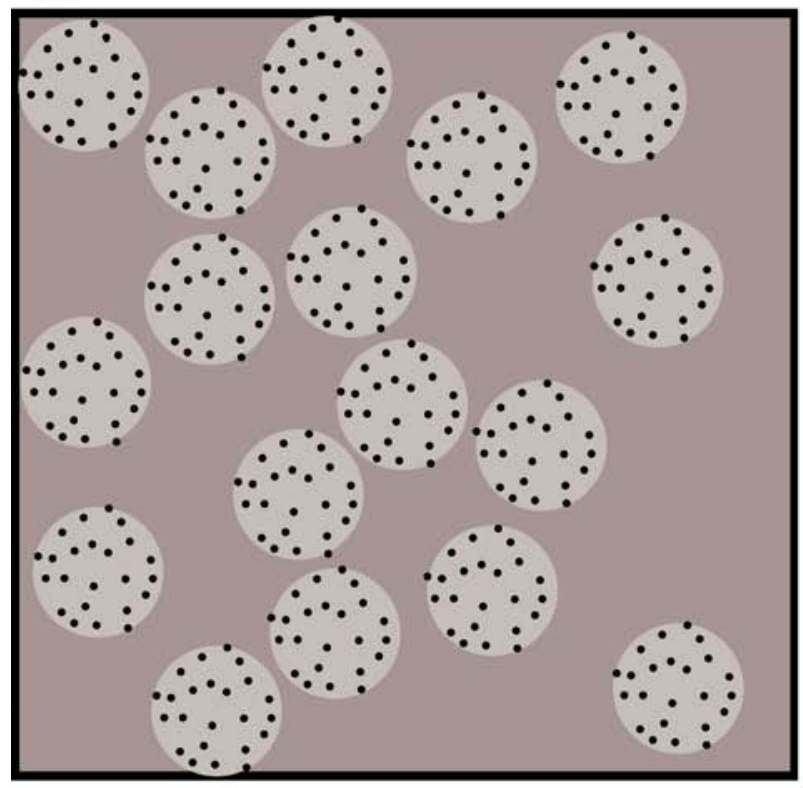

c)

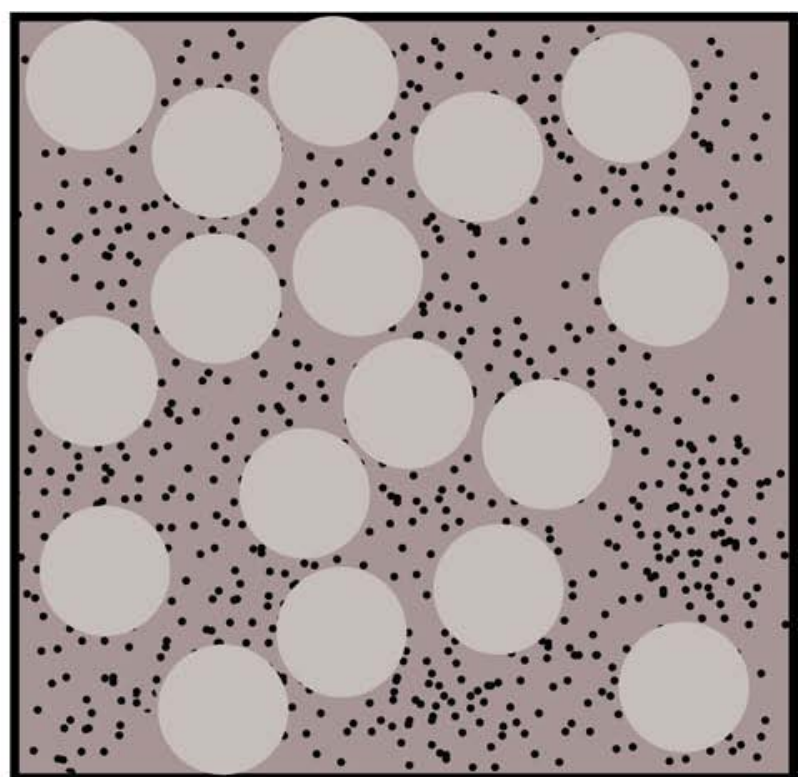

b)

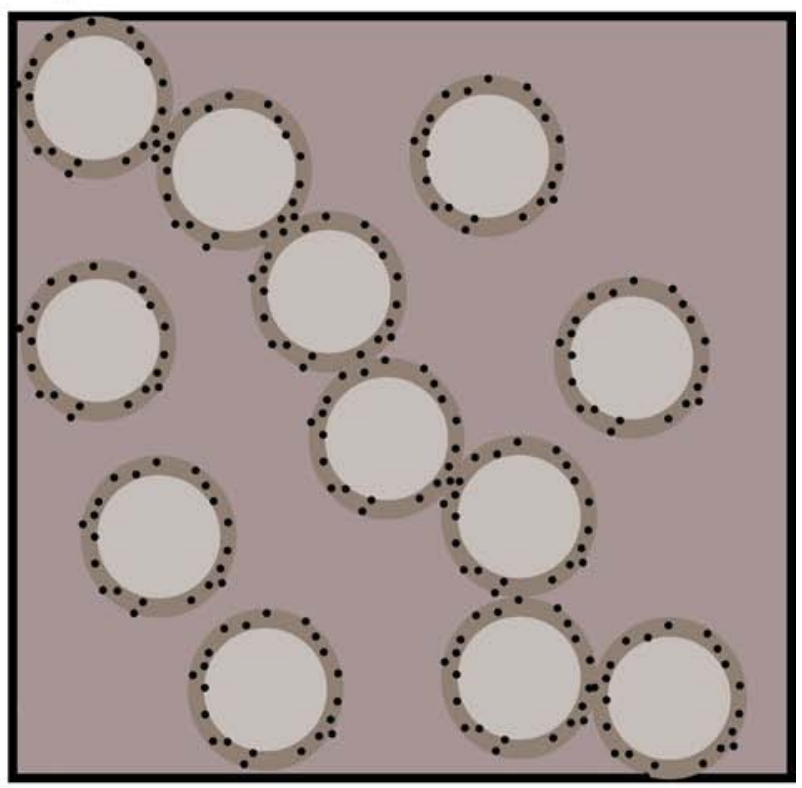

d)

Figure 1. Schematic of different types of loading with conductive fillers: a) bulk loading, b) fibrillar polymer-polymer composite in which only the matrix is loaded (matrix loading), c) as b), but only the reinforcing fibrils are loaded (microfibrils loading), and d) as b) but only the compatibilizer is loaded (interfacial loading); the views are perpendicular to the extrusion direction

ing), which lowered the percolation threshold [19]. In this way it was demonstrated that for the blend $\mathrm{PE} / \mathrm{PET}$ and conductive filler $\mathrm{CB}$ the threshold percolation is $11 \mathrm{vol} \%$ when both, the PE and PET are loaded [44], 5.2 vol\% CB when only PET microfibrils are loaded [11], and only 3.5 vol\% when $\mathrm{CB}$ particles are selectively distributed around the microfibril surface [45].

The main goal of this study is to compare the electrical conductivity for three different cases of loading with conductive filler the basic elements of a poly- mer-polymer composite, namely the matrix only, the microfibrils only, and the compatibilizer only, i.e. to realize the three cases of bulk loading, microfibrils loading and interfacial loading (Figure 1).

It should be noted that the conducting filler in the current study are CNTs of multi walled type. Further on, in contrast to the studies of Li and coworkers [11, 44, 45], who found increased concentrations of $\mathrm{CB}$ on the interface, in the present study a 'special carrier' for delivering of CNTs to the same location, the interface between matrix and reinforc- 
ing microfibrils, will be used - a suitable compatibilizer loaded with CNTs.

An additional task of the study is to find an appropriate technique for introducing the compatibilizer into the blend, thus avoiding the known negative effect of compatibilizers on the microfibrils formation.

\section{Experimental}

\subsection{Materials}

The materials used include PP, conductive grade poly(butylene terephthalate) (PBT) loaded with CNTs, PET and neat PP-g-MA and CNT-loaded PPg-MA. The details of the materials are as follows.

Two grades of PP were used, both supplied by Lyondell Basell of Corio, Australia: HP555G grade (melt flow index (MFI) of $1.3 \mathrm{~g} / 10 \mathrm{~min}$, ultimate tensile strength (UTS) of $35 \mathrm{MPa}$ ) denoted further as high viscous PP (PPhv) and the lower viscous HP548S grade (MFI $35 \mathrm{~g} / 10 \mathrm{~min}$, UTS $33 \mathrm{MPa}$ ) denoted as PPlv.

PBT of grade SR 525 loaded with $5 \mathrm{wt} \%$ CNTs (manufacturer tested volume resistivity of $6.61 \Omega \cdot \mathrm{cm}$ ) was supplied by Hyperion Catalysis International, Cambridge, USA. The CNTs were of type FIBRIL ${ }^{\mathrm{TM}}$ nanotubes (type MWCNT, diameter $\sim 10 \mathrm{~nm}$, density $\left.1.66 \mathrm{~g} / \mathrm{cm}^{3}\right)$.

PET of grade Shinpet $5015 \mathrm{~W}$ (density $1.4 \pm 0.1 \mathrm{~g} / \mathrm{cm}^{3}$ ) was supplied by Shinkong Synthetic Fibres Corporation, Taiwan.

PP-g-MA was of grade Orevac 18732 (MFI $8 \mathrm{~g} / 10 \mathrm{~min}, \mathrm{UTS} 20 \mathrm{MPa}$ ). PP-g-MA was melt-mixed with $5 \mathrm{wt} \%$ CNTs to generate a conductive compatibilizer. The CNTs used were of grade Nanocyl ${ }^{\mathrm{TM}}$ NC7000 (type MWCNT, diameter $\sim 10 \mathrm{~nm}$, density $1.75 \mathrm{~g} / \mathrm{cm}^{3}$ [46]), supplied by Nanocyl SA, Sambreville, Belgium.

\subsection{Sample preparation}

The samples had to be prepared in such a way to allow the conductivity measurements of the three basic types of loading, namely, bulk loading, fibrils loading, and interfacial loading (Figure 1). Please refer to Table 1 for a list of the samples prepared, and the designations used for them in the paper.

\subsubsection{Samples with bulk loading}

For this type of samples, one polymer melt mixed with CNTs was used, corresponding to Figure 1a. PBT granules containing $5 \mathrm{wt} \%$ of MWCNTs, as supplied by the manufacturer, were compression moulded at $180^{\circ} \mathrm{C}$ and pressure of $7 \mathrm{MPa}$ to produce samples with sizes of $10 \mathrm{~mm} \times 80 \mathrm{~mm} \times 0.3 \mathrm{~mm}$ suitable for measuring the electrical conductivity.

\subsubsection{Samples with fibrils loading}

For this purpose PP was used as matrix and PBT/ $\mathrm{CNT}$ as reinforcing fibrils. The standard MFC protocol was used [47], namely both grades of PP and PBT were dried at 80 or $110^{\circ} \mathrm{C}$, respectively, dry-mixed to a weight ratio of $70 / 30$, followed by melt blending at $265^{\circ} \mathrm{C}$ in a Brabender DSE20 twin-screw extruder with $25 \mathrm{~mm}$ screw, and an $L / D$ ratio of 40 and $5 \mathrm{rpm}$, using a $1.3 \mathrm{~mm}$ die. The extrudate was cooled in water bath immediately after its exit from the die. The extruded blend was then subjected to cold drawing at $80^{\circ} \mathrm{C}$ to ratios between 4.7 and 5 , using two winders and a $2 \mathrm{~m}$ long heated chamber. Cold drawing was followed by isotropization of the matrix - the drawn blend was wound uniaxially on a plate, followed by compression moulding at $180^{\circ} \mathrm{C}$ to a sheet with a thickness of about $0.3 \mathrm{~mm}$. Thus, MFC samples with microfibril reinforcement were manufactured. The next series of MFC samples using the second type of $\mathrm{PP}$ was prepared in the same way.

A small amount of each PP/(PBT/CNT) blend, after cold-drawing was subjected to removal of PP using hot xylene in a modified Soxhlet apparatus according to a procedure described in [48].

From the $\mathrm{PP} /(\mathrm{PBT} / \mathrm{CNT}) \mathrm{MFC}$ sheet, specimens of $10 \mathrm{~mm} \times 80 \mathrm{~mm} \times 0.3 \mathrm{~mm}$ (length direction along direction of cold-drawing) were cut to test the electrical conductivity.

\subsubsection{Samples with interfacial loading}

As mentioned in the introduction, in order to guarantee a more precise localization of CNTs just on the interface boundary, a 'special carrier' has been used, a compatibilizer of the type PP-g-MA, which, due to its peculiar chemical composition, positions itself at interface between the matrix and the microfibrillar reinforcement only.

At the same time, as noted above, the use of compatibilizer during the MFC manufacturing is not recommendable since it has a negative effect on the microfibrils formation via preventing the coalescence of the starting spherical particles during the drawing stage [36]. For this reason it had to be checked firstly the recommendation given in ref. [36], namely, to add the compatibilizer to the blend 
Table 1. Blend designations and the constitution of the composites and blends by weight

\begin{tabular}{|c|c|c|c|}
\hline No. & Blend designation & Components & $\begin{array}{l}\text { Component content in the } \\
\text { composite/blend [wt \%] }\end{array}$ \\
\hline 1 & $\mathrm{PBT} / \mathrm{CNT}$ & $\begin{array}{l}\text { PBT } \\
\text { CNT (Hyperion) }\end{array}$ & $\begin{array}{r}95 \\
5\end{array}$ \\
\hline 2 & PP-g-MA/CNT & $\begin{array}{l}\text { PP-g-MA } \\
\text { CNT (Nanocyl) }\end{array}$ & $\begin{array}{r}95 \\
5\end{array}$ \\
\hline 3 & $\mathrm{PPhv} /(\mathrm{PBT} / \mathrm{CNT})$ & $\begin{array}{l}\text { PP, high viscosity } \\
\text { PBT/CNT }\end{array}$ & $\begin{array}{l}70 \\
30\end{array}$ \\
\hline 4 & $\mathrm{PPlv} /(\mathrm{PBT} / \mathrm{CNT})$ & $\begin{array}{l}\text { PP, low viscosity } \\
\text { PBT/CNT }\end{array}$ & $\begin{array}{l}70 \\
30\end{array}$ \\
\hline 5 & $\mathrm{PP} /(\mathrm{PBT} / \mathrm{CNT})$ & \multicolumn{2}{|c|}{ Refers to blends 3 and 4} \\
\hline 6 & $\mathrm{PPhv/PET}$ & $\begin{array}{l}\text { PP, high viscosity } \\
\text { PET }\end{array}$ & $\begin{array}{l}70 \\
30\end{array}$ \\
\hline 7 & PPlv/PET & $\begin{array}{l}\text { PP, low viscosity } \\
\text { PET }\end{array}$ & $\begin{array}{l}70 \\
30\end{array}$ \\
\hline 8 & PP/PET & \multicolumn{2}{|c|}{ Refers to blends 6 and 7} \\
\hline 9 & $\mathrm{PPhv/PET/(PP-g-MA/CNT1)}$ & $\begin{array}{l}\text { PPhv/PET } \\
\text { PP-g-MA/CNT }\end{array}$ & $\begin{array}{r}95 \\
5\end{array}$ \\
\hline 10 & $\mathrm{PPhv/PET/(PP-g-MA/CNT2)}$ & $\begin{array}{l}\text { PPhv/PET } \\
\text { PP-g-MA/CNT }\end{array}$ & $\begin{array}{l}90 \\
10\end{array}$ \\
\hline
\end{tabular}

only after the drawing stage and subject the new blend to a reprocessing including re-extrusion at lower temperature and redrawing. This reprocessing requires an additional checking regarding the safe existence of the microfibrils created during the first processing. Only thereafter it is meaningful to repeat the same scenario using a compatibilizer loaded with CNTs.

For the samples with interfacial loading the best studied MFC system was used - PP as a matrix and PET as reinforcement. PP-g-MA loaded with CNTs was used as blend compatibilizer. The PP/PET/(PPg-MA/CNT) blends were prepared in the following way:

The compatibilizer PP-g-MA loaded with $5 \mathrm{wt} \%$ CNTs was prepared using melt mixing in a Berstorff ZE25 co-rotating twin-screw extruder with $L=36 \mathrm{D}$ at a throughput of $10 \mathrm{~kg} / \mathrm{h}$ and a rotation speed of $500 \mathrm{rpm}$. PP granules and CNT powder were added into the hopper as premixtures and the temperatures were set to be between 200 and $180^{\circ} \mathrm{C}$ (from the hopper to the die). The conductivity of this composite as measured on compression moulded sheets is well in the percolated range (about $10 \Omega \cdot \mathrm{cm}$ [49]). For the preparation of blends of interest, the respective components as PP, PP-g-MA/CNT and PET were dried prior to processing at 80 and $110^{\circ} \mathrm{C}$ (PET). The PP/PET microfibrillar drawn blend was first prepared using the same method described in section 3.2.2., and pelletized to sections of $3 \mathrm{~mm}$ length.
Some of the pelletized material of the drawn PP/PET blend was subjected to a second melting in the extruder at $215^{\circ} \mathrm{C}$ (below the melting temperature of PET). From the extrudate, a small piece was subjected to cryofracture in liquid nitrogen, and the cross-sections was cut out. A small portion of the PP/PET after the first processing was subjected to removal of PP using hot xylene [46]. These samples were inspected by SEM to confirm the preservation of the fibrils in the re-extruded PP/PET blend.

Once this was confirmed, the remaining pelletized material of PP/PET drawn blend was dry-mixed with PP-g-MA/CNT, to 95/5 and 90/10 weight ratios and re-extruded. The re-extruded blends were redrawn at $80^{\circ} \mathrm{C}$ to a draw ratio of around 3.5 , wound uniaxially on a plate, followed by compression moulding at $180^{\circ} \mathrm{C}$ and a nominal pressure of $7 \mathrm{MPa}$ in a hydraulic press to obtain sheets with MFC structure.

\subsection{Sample characterization}

Strips from the various types sample sheets with MFC structure with dimensions of $10 \mathrm{~mm} \times 50 \mathrm{~mm}$ $\times 0.3 \mathrm{~mm}$ (length direction along direction of colddrawing), were cryofractured in liquid nitrogen, and the cross sections were mounted on adhesive stubs. Specimens for the SEM were coated with colloidal platinum for $10 \mathrm{~min}$ prior to observation and loaded into a Philips/FEI FEG-XL30S scanning electron microscope. Micrographs were taken at different locations of each specimen at different magnifications. 
Electrical conductivity was characterized using a four-point test rig (ASTM D4496). As mentioned earlier, specimens of dimensions $10 \mathrm{~mm} \times 80 \mathrm{~mm} \times$ $0.3 \mathrm{~mm}$ (length direction along direction of colddrawing) were prepared. Silver paste was spread on the specimens on the lines of contact with the sharp edged contacts of the rig. The rig was connected to a constant current source (Keithley 220, Keithley, Ohio, USA) or a high resistance electrometer (Keithley 6517A, Keithley, Ohio, USA).

\section{Results and discussion}

\subsection{Effect of matrix viscosity and the presence of compatibilizer on microfibril formation: Morphological characterization}

$\mathrm{PP}$ was removed from both the PPhv/(PBT/CNT) and $\mathrm{PPlv} /(\mathrm{PBT} / \mathrm{CNT})$ blends for SEM characterization. The remaining microfibrils of PBT loaded with CNT were inspected by means of SEM for getting an idea about their thickness and length. The results are shown in Figure 2. The fibrils prepared from the $\mathrm{PPhv} /(\mathrm{PBT} / \mathrm{CNT})$ blend (Figure 2a) are rather thin (diameters between 250 and $500 \mathrm{~nm}$ ) thus approaching the nano-range, while those from the PPlv/ (PBT/CNT) blend (Figure 2b) are considerably thicker and have thicknesses between 1 and $5 \mu \mathrm{m}$. At the same time, the second type of fibrils seem to be smoother (Figure $2 b$ ) and possibly longer than those of the first type (using PPhv), Figure 2a. This difference can be explained by the matrix viscosity of the two PPs, whereby the higher viscous matrix generates due to higher shear stresses acting on the disperse phase smaller particles available for later coalescence. In addition, the PP with higher viscos-

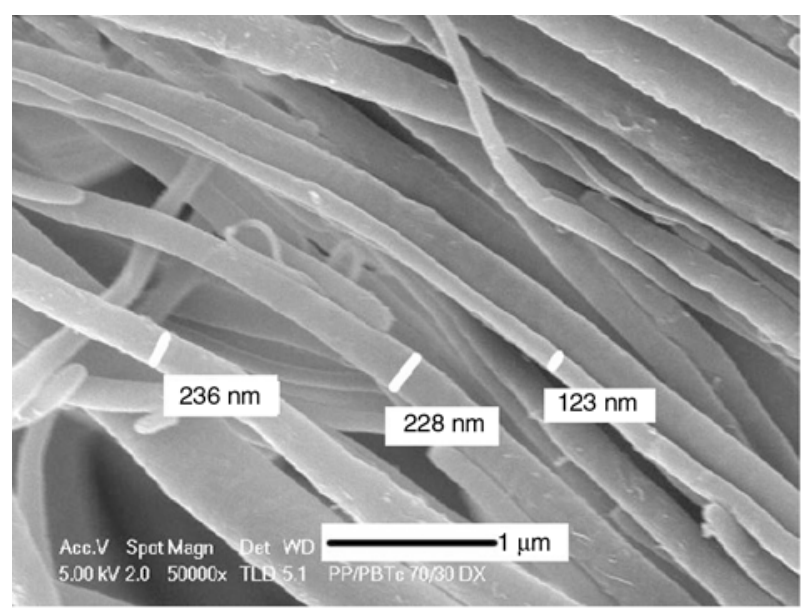

a) ity offers better conditions for the microfibril formation during cold drawing (around $T_{\mathrm{g}}$ of PBT or PET) as compared to the lower viscous matrix PP in sense of more effective coalescence. The coalescence is the crucial process for the formation of microfibrils - without coalescence the cold drawing results in formation of elliptical particles with aspect ratio of 2-4 (Figure 4b).

It should be mentioned that the microfibrils of Figure 2 are the reinforcing component of the polymerpolymer composites of MFC type, which could be prepared from the drawn blend via compression moulding at temperatures when PP only melts.

The cryofracture surfaces of the manufactured MFCs in the direction perpendicular to the drawing direction for the two types of PP are shown in the SEM micrographs in Figure 3. Comparing the two types of composites, namely applying PPhv (Figure 3a) and PPlv (Figure 3b), a substantial difference in the structure of the cross-section surface can be observed. In the first case (Figure 3a), the fibrils are much thinner, up to ten times as compared to the second type (compare Figure $3 \mathrm{a}$ and $3 \mathrm{~b}$ ), which is in agreement with the results of comparison of the extracted fibrils (Figure 2). Furthermore, the cryofracture in the first case occurs with dominating pull out of fibrils from the matrix (Figure 3a), contrasting to that of the second case (Figure $3 b$ ) where break of the microfibrils is more evident. And finally, in the second case due the fibril's break one can see the carbon nanotube loading in the PBT microfibrils (Figure 3b, inset). In this way, polymer-polymer composites (PPCs) of MFC type were successfully prepared, in which only the microfibrils are loaded with CNTs

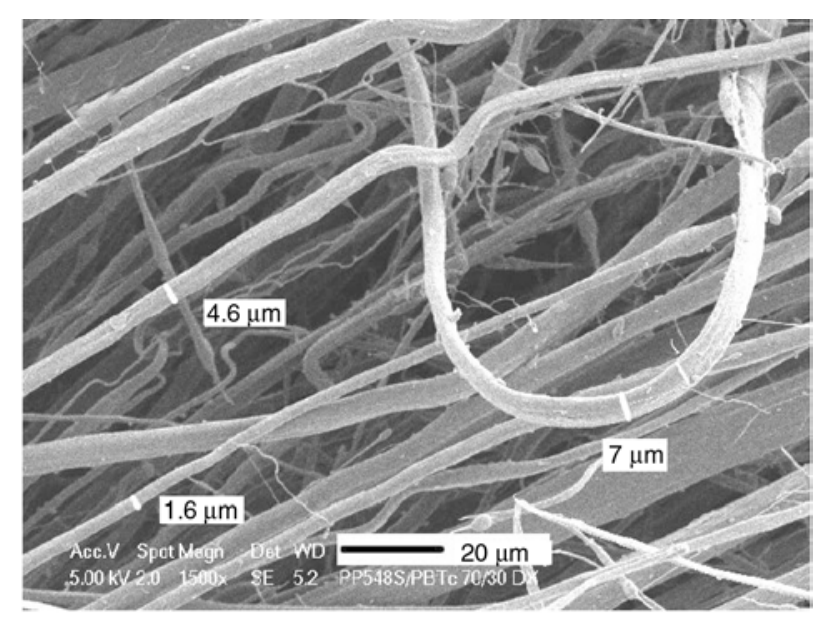

b)

Figure 2. SEM micrographs of fibrils prepared from PP/(PBT/CNT) (70/(95/5) wt \%) after extraction of PP: a) from blend containing high viscosity PPhv, and b) from blend containing low viscosity PPlv 


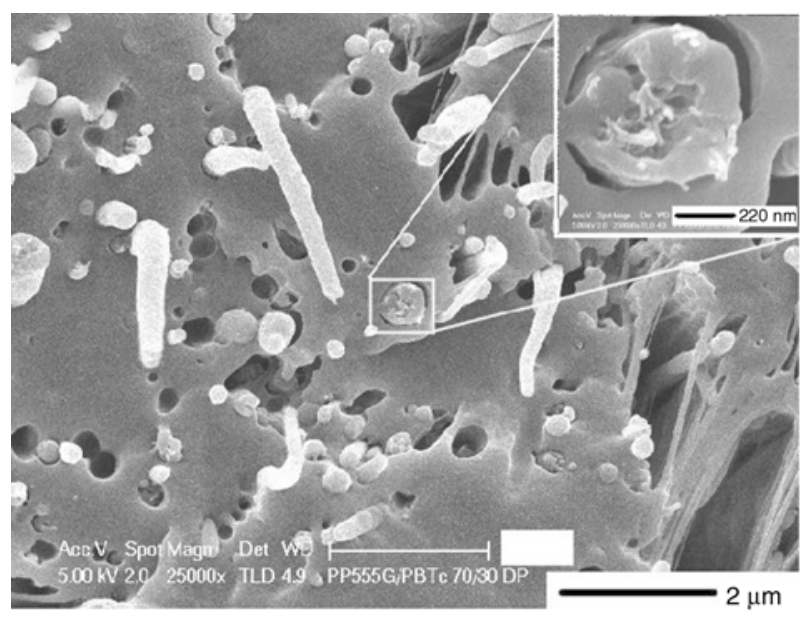

a)

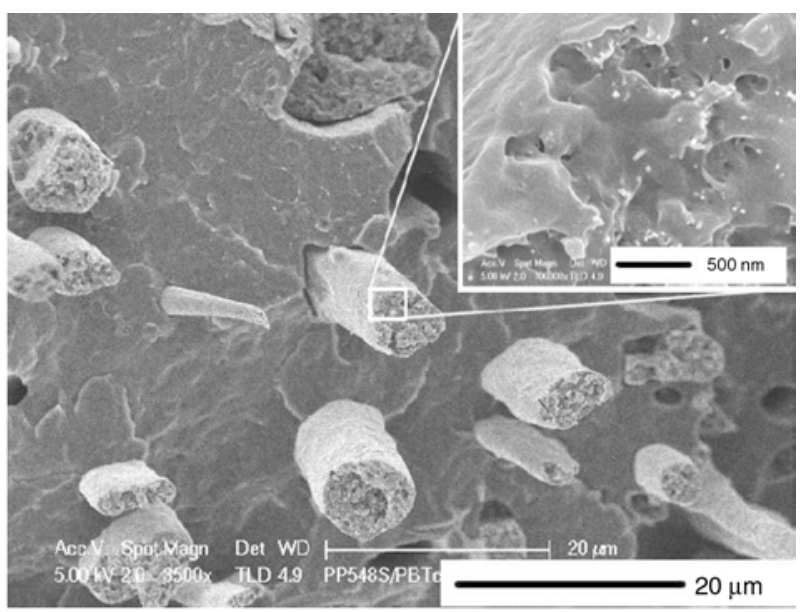

Figure 3. SEM micrographs of cryofractured cross-sections of $\mathrm{PP} /(\mathrm{PBT} / \mathrm{CNT})(70 /(95 / 5) \mathrm{wt} \%)$ drawn blend after compression moulding (isotropization step) using two types of PP: a) high viscosity PPhv and b) low viscosity PPlv, with insets at higher maginifications

(Figure 3b), following the previous experience with a blend of PP and CNT-loaded polyamide-6,6 [40]. The difference between the two studies is that the masterbatch of PBT/CNT used in the current study is of conductive type, and the previous one was not. In this way, in addition to samples with bulk loading (Figure 1a), we have the second candidate (Figure 1c) for the comparative study, and only the third type, with interfacial loading of fillers (Figure 1d) is missing.

Many researchers [11, 17, 19, 43] published results of similar studies, where they prepared polymer blends with MFC structure, loading with carbon black either the microfibril forming component (PET) or the matrix (PE) in amounts between 3 and $13 \mathrm{vol} \%$. They found an accumulation of $\mathrm{CB}$ at the interfacial layer, so that a higher $\mathrm{CB}$ concentration

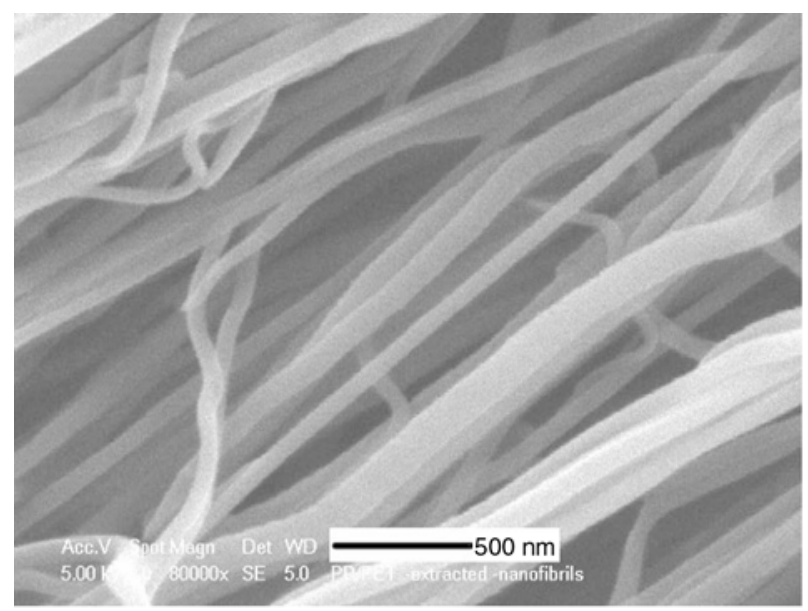

a) as compared to that of the microfibrils or the matrix was reached at the interface.

Contrasting these studies [11, 17, 19, 43], our main target was to deliver the conductive filler (CNTs) more precisely - only to the interface between reinforcement and matrix as mentioned above. Towards this target, a compatibilizer was chosen as the carrier of CNTs. Compatibilizers being in nature and action surfactants, have a molecule designed in such a way that one part is 'friendly' with one of the blend components, and another part with the other blend component. It can only fulfill this target by localizing at the interface The driving force for the migration to the interface is the diphilic character of the molecule - the homogeneous one-component medium is not the final localization place. During the migration process, it is quite possible that the

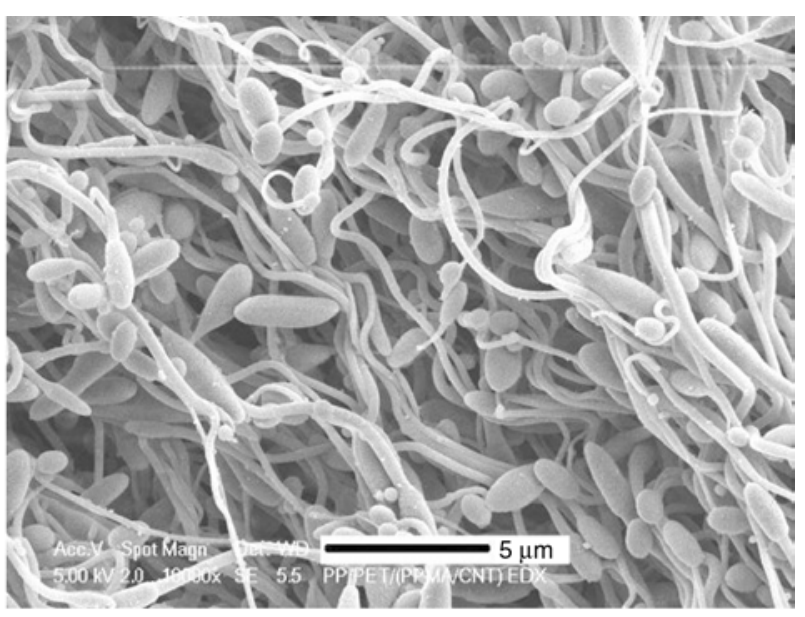

b)

Figure 4. SEM micrographs of PET microfibrils extracted using hot xylene from drawn PPhv/PET blend: a) blend without compatibilizer, and b) blend containing PP-g-MA compatibilizer in the amount of $5 \mathrm{wt} \%$ referred to the total blend 
compatibilizer loses part of its CNTs, particularly if the concentration gradient is very high. However, interactions between functional groups on the surface of the MWCNTs and the MA groups of the compatibilizer can fix the CNTs within the compatibilizer phase [34]. At the same time, the compatibilizer inhibits the formation of microfibrils [36] as demonstrated also by the results of the current study. In Figure 4 one can see well defined nanofibrils (Figure 4a) if the MFC material is prepared without the use of compatibilizer. In the presence of compatibilizer, mostly elliptical particles can be seen (Figure 4b) instead of smooth 'endless' nanofibrils. These samples were prepared to illustrate the effect of presence of compatibilizer on fibril formation, and do not contain CNTs.

Taking into account the mechanism of fibril formation - via stretching and coalescence of the starting spherical or elliptical particles [36], the result displayed in Figure $4 \mathrm{~b}$ becomes quite clear. The inhibiting effect of the compatibilizer consists of coating the spherical particles with a thin film, which prevents their coalescence even if in contact. This situation is quite normal, if one remembers that the main task of the compatibilizers is to enhance and stabilize the dispersion of two thermodynamically immiscible liquids via prevention of coalescence of droplets. This inhibiting effect of the compatibilizer on fibril formation had to be overcome when dealing with MFCs manufacturing.

\subsection{MFCs with interfacial CNT loading: Morphological characterization}

The above defined problem regarding the inhibiting effect of the compatibilizer on nanofibril formation

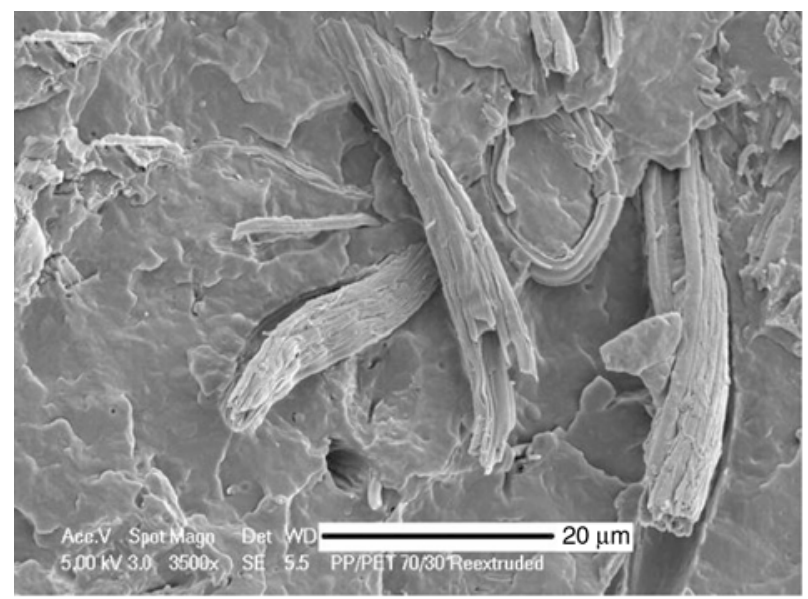

a) was solved following the recommendation given in [36], namely to add the compatibilizer to the blend after fibril formation. In such a case the processing steps will be in the following order: melt blending of the two starting polymers, extrusion, cold drawing, pelletizing, mixing with the compatibilizer, drying, remelting, re-extrusion and redrawing.

Before applying this more complex processing route using a compatibilizer loaded with CNTs, the effect of the repeated treatment on the structure of the MFCs was examined. Due to the properly selected reprocessing temperature $\left(215^{\circ} \mathrm{C}\right)$, the previously created PET fibrils were completely preserved (Figure 5).

The only change observed is that they exist as twisted bundles after the reprocessing the drawn blend. Having these results, it was possible to perform the same reprocessing using the PP-g-MA compatibilizer loaded with $5 \mathrm{wt} \%$ CNTs.

The cryofractured surfaces of the drawn PPhv/PET/ (PP-g-MA/CNT1) blend (Table 1) are shown in Figure 6 . The main task of this microscopic inspection of the prepared samples was to find reliable proofs for the proper localization of the CNTs delivered by the compatibilizer - just at the interface between the matrix (PP) and the reinforcing microfibrils (PET). For this purpose, SEM micrographs are taken from various spots using increasing magnifications. The fibrils appear to be coated by the PP matrix in most cases, as in the case of the bundle shown in Figure 6a. The CNTs can be seen only on the surface of the fibrils (Figure 6b) as a random network, coated by the compatibilizer (Figures $6 \mathrm{c}-$ 6f). This gives an idea that the CNT filler has indeed localized near the interface of PP matrix and PET reinforcement, as desired.

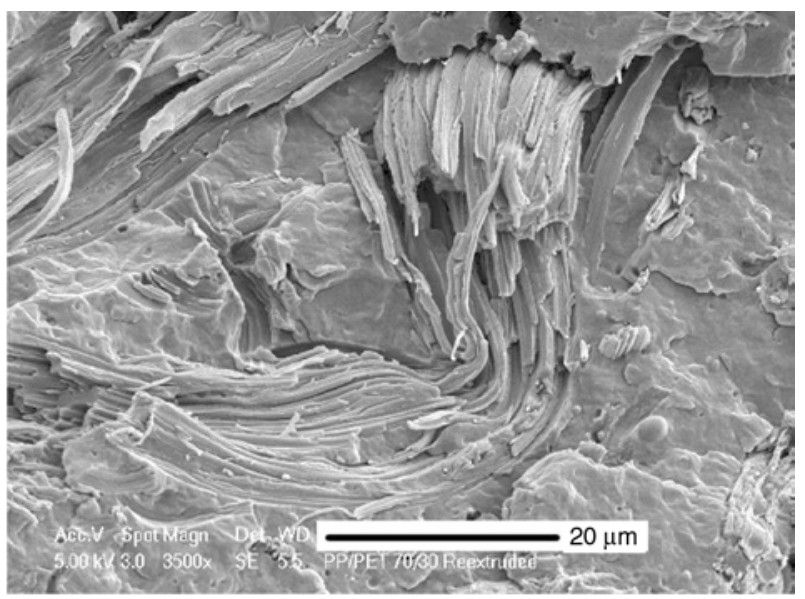

b)

Figure 5. SEM micrographs of cryofractured cross-sections of remelted and re-extruded MFC based on PPhv/PET (70/30 by weight). a) twisted bundles of PET nanofibrils in PP matrix, b) nanofibrils forming the bundles 


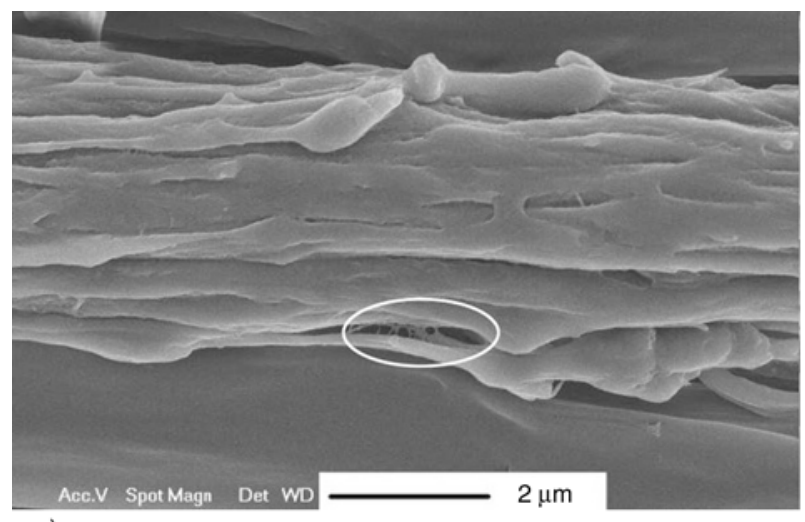

a)

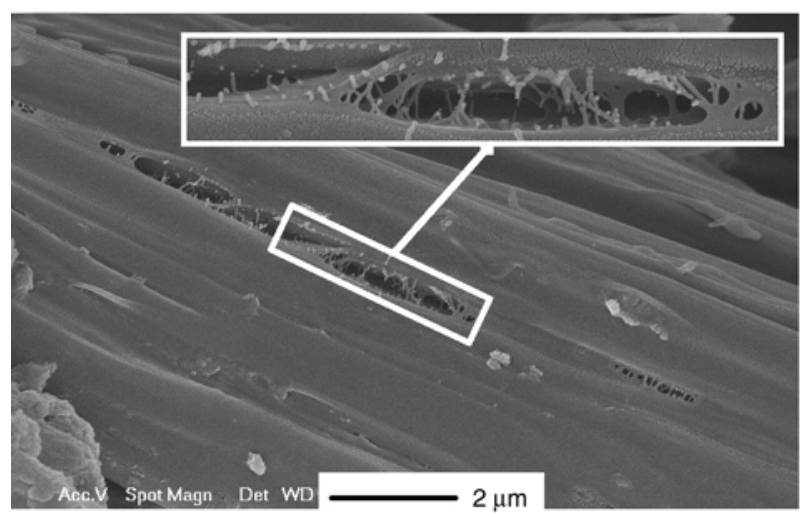

c)

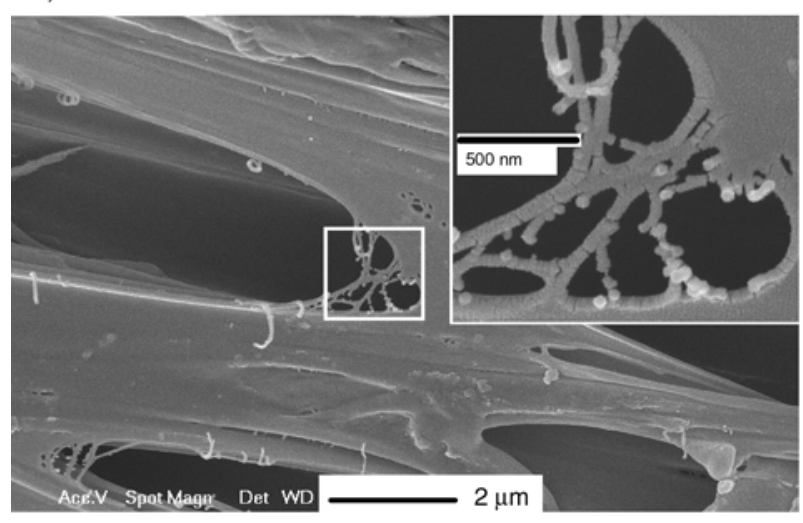

e)

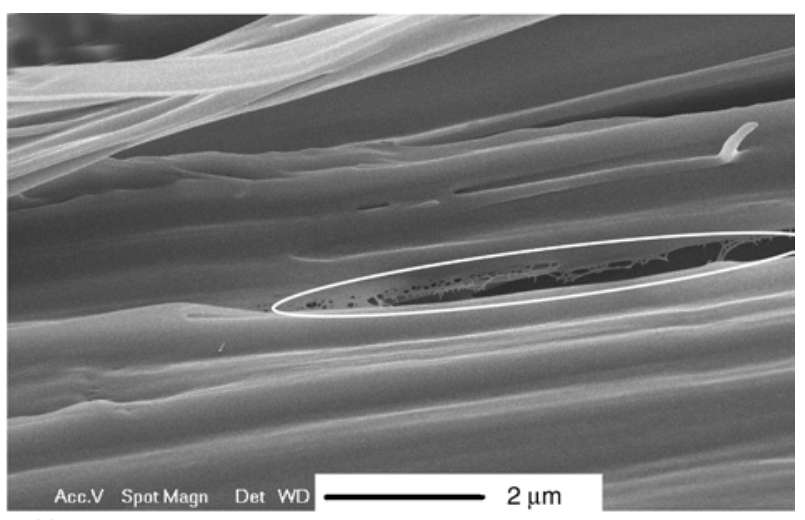

b)

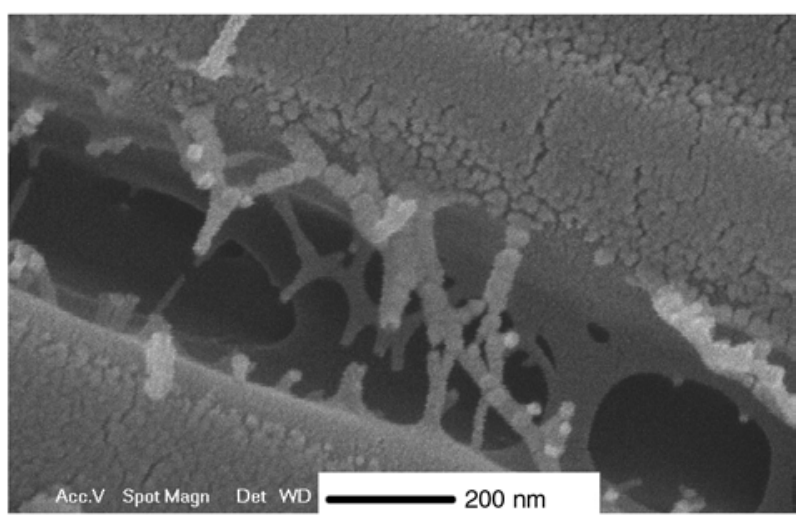

d)

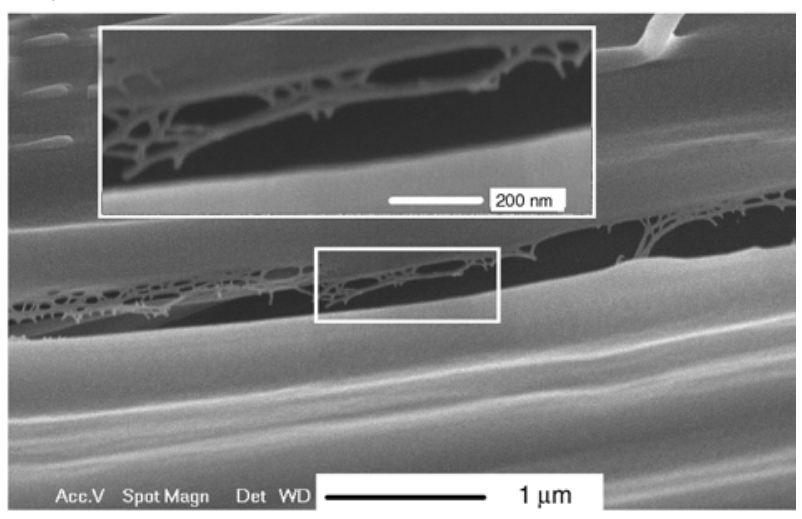

f)

Figure 6. SEM micrographs of cryofractured longitudinal sections of drawn blend based on PPhv/PET/(PP-g-MA/CNT1). The micrographs are taken from different spots of the sample at various magnifications (see the insets)

However, the best proof for the presence of CNTs in this material will be the positive results of the electrical measurements as well as their comparison with the non-compatibilized polymer blend containing CNTs in the fibrils only.

\subsection{Electrical properties of the blend PPhv/PET/(PP-g-MA/CNT)}

The testing of the electrical properties of the prepared materials was performed on specimens from sheets manufactured by compression molding at such a temperature as to melt PP only, thus forming a polymer-polymer composite of MFC type.

All the materials tested contained MWCNTs but dispersed in different structural elements of the MFCs, namely: i) in the microfibrils alone (microfibril loading, Figure 1c), ii) in the compatibilizer only (interfacial loading, Figure 1d), and (iii) in the matrix polymer only (bulk loading, one polymer blended with CNTs, Figure 1a), using the as supplied PBT/ CNT blend. Further on, the microfibrils loaded samples were prepared using the two grades of PP 
(PPhv and PPlv). These are denoted as PPhv/(PBT/ $\mathrm{CNT})$ and $\mathrm{PPlv} /(\mathrm{PBT} / \mathrm{CNT})$.

Figure 7 shows the electrical resistivities of the samples produced in this study, which all were made under comparable pressing and measurement conditions. In order to judge the results, these results are plotted together with references from literature, for which the $\mathrm{wt} \%$ were recalculated in vol\% in order to compare materials with matrices of different densities. Of course, the mixing, compression molding and measurement conditions of the composites taken from literature were partially different from those in this study and this comparison has to be taken with care. Also the resistivities of the neat polymers differ. However, this comparison enables to compare the results of this study with electrical percolation results from literature.

The respective values of the volume resistivity for the microfibrils loaded case (Figure 1c) are $1.5 \cdot 10^{7} \Omega \cdot \mathrm{cm}$ (for PPhv/(PBT/CNT)) and 1.9 $10^{6} \Omega \cdot \mathrm{cm}$ (for PPlv/ (PBT/CNT)). Both values are in the electrostatic dissipative range, i.e., between $10^{4}-10^{12} \Omega \cdot \mathrm{cm}$ [50]. The sample comprising the lower viscosity matrix (PPlv) is characterized by a volume resistivity an order of magnitude lower than the sample with the higher viscosity matrix (PPhv). This difference could be due to the difference in microfibril diameters between the two types of MFCs which were 10-
20 times lower in the case of PPhv. Having in mind the fact that the concentration of the CNTs in the two types of fibrils is the same (5 wt\%), the preparation of $\mathrm{PBT}$ nanofibrils using the $\mathrm{PPhv}$ matrix generates in the thinner fibrils higher draw ratios and thus higher orientation of both the macromolecules and CNTs as compared to PPlv. Orientation of CNTs along the fiber axis was found in melt spun fibers to increase the resistivity [51] due to the reduced number of contacts between the individual CNT particles.

What the second basic case of interest, the interfacial loading (Figure 1d) concerns, it should be noted that higher values of resistivity $\left(2.87 \cdot 10^{8}\right.$ and $\left.9.93 \cdot 10^{7} \Omega \cdot \mathrm{cm}\right)$ as compared with the case of microfibrillar loading (Figure 1b) are obtained for the two samples prepared with PPhv only and denoted as PPhv/PET/(PP-g-MA/CNT1) and PPhv/PET/(PPg-MA/CNT2), where 1 and 2 represent 5 and $10 \mathrm{wt} \%$ compatibilizer added to PP/PET blends, respectively.

Starting from the fact that the two values of the volume resistivity obtained for the two concentrations of compatibilizer are rather close to each other, one can conclude that the amount of compatibilizer itself does not affect the electrical properties that strongly. As the compatibilizer itself is conductive (with $5 \mathrm{wt} \%$ CNTs well above percolation) and pro-

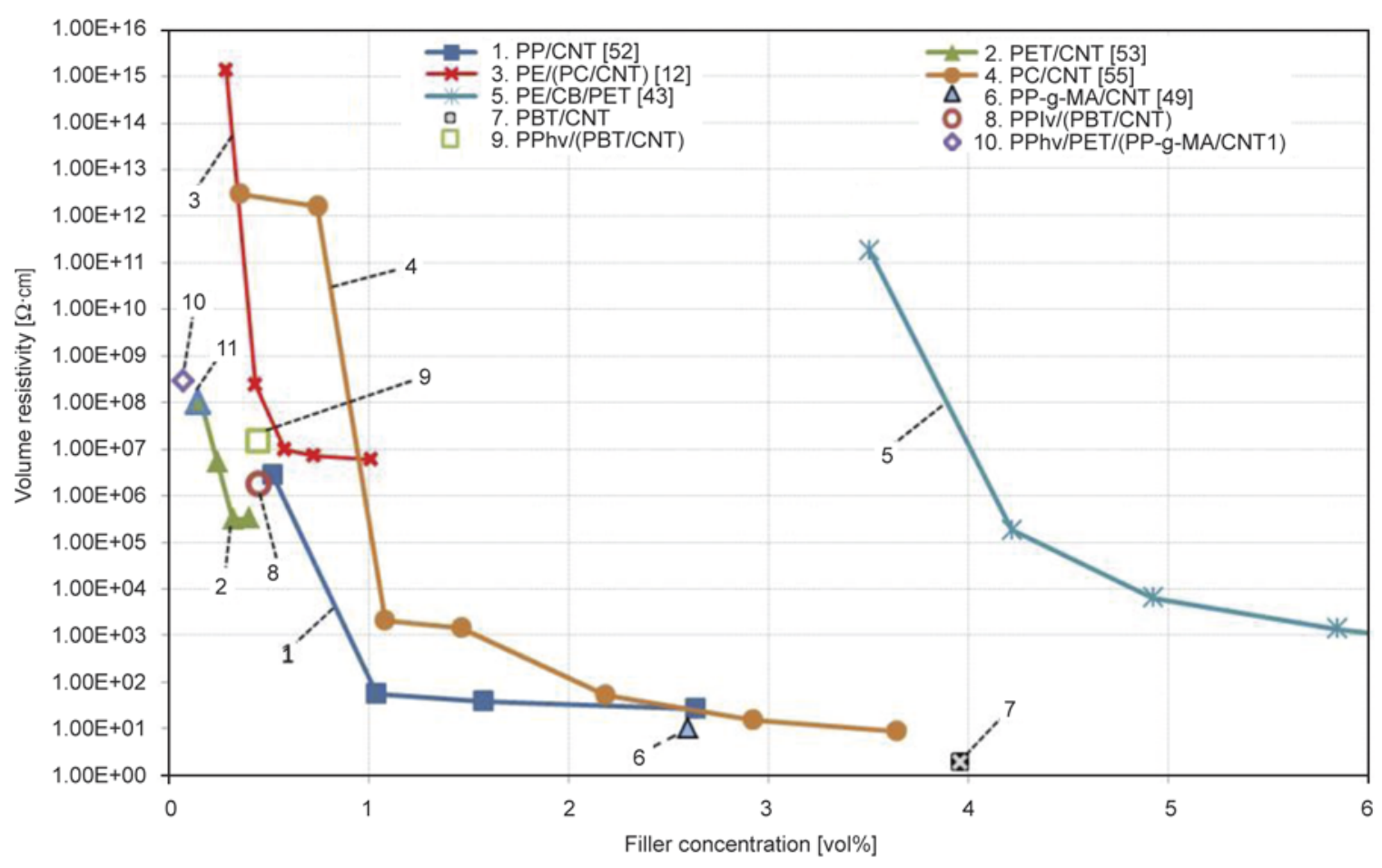

Figure 7. Dependence of volume resistivity on the filler concentration in various polymeric materials loaded with CNTs or CB 
vides the conductive path through the sample, the amount of compatibilizer seems to be not so important. This finding also implies indirectly, that the compatibilizer covers the surface of the fibrils in a sufficient way to reach conductivity in the whole sample. At the same time, it is well documented that the compatibilizer, particularly in increased concentrations, has a deteriorating effect on the mechanical performance of polymer-polymer composites. This will mean that a good balance between the electrical and mechanical properties of the same material could be expected via using compatibilizers with higher CNT loading and possibly lower compatibilizer concentrations in the MFC material. An idea of how the values of volume resistivity from samples prepared in this study are related to the typical percolation thresholds of similar systems could be got from Figure 7. Samples 1-6 refer to published data [12, 43, 49, 52-55], whereas sample 6 represents the compatibilizer material used in this study, and samples 7-10 are from the present study. In the majority of cases the conductive filler is dispersed in the polymer bulk (Figure 7, samples 1, 2, $4,6,7)$, in some cases only in the reinforcing microfibrils within MFCs (Figure 7, samples 5, 8, 9) or in one phase of co-continuous blends (Figure 7, sample 3), and only in two cases (present study) in the compatibilizer within MFCs (Figure 7, samples 9 and 10).

One can see that the resistivity values of the blends with MFC structure tested in this study (Figure 7, samples 8-11) are near or lower than the values of the percolation threshold for $\mathrm{PE} /(\mathrm{PC} / \mathrm{CNT}$ ) (Figure 7, sample 3), 1-3 orders of magnitude away from the threshold for PET/CNT (Figure 7, sample 2), 3-5 order of magnitude away from the threshold for $\mathrm{PP} / \mathrm{CNT}$ (Figure 7, sample 1). The curves in Figure 7 demonstrate the extremely strong dependence of the volume resistivity on the concentration of the filler - a change of CNT concentration by 1 vol $\%$ can result in a decrease of the resistivity by up to 10 orders of magnitude. This bodes well for MFC blends which will be prepared in a future study, with higher CNT loadings.

Another peculiarity of the polymer conductive materials is their sensitivity to many other factors affecting their electrical conductivity, including also such a 'secondary' factor as pressing conditions.
For this reason a more detailed comparison of the obtained data with the reported ones is hardly justified. Nevertheless, the results obtained in the current study look quite promising because they demonstrate the possibility of obtaining reasonable values for the electrical conductivity when loading conductive filler only in the minor component of the fibrils containing blend or in the interfacial area of such microfibrillar blends. Such an approach also allows avoiding or decreasing drastically the deterioration effect of CNTs on the mechanical properties of the polymer blends. In addition, when working with polymer blends having MFC structure, one is getting considerable improvement of mechanical properties, particularly when the matrix is a polyolefin $[37,39]$. In this way, applying the MFC concept to polymer blends, we observe a dual benefit, namely improvement of mechanical performance via fibrils reinforcement and avoiding the detrimental effect of CNTs using microfibrils or compatibilizer loading only for improving the functional properties of the polymer blend.

The further steps of this study will be in the direction of finding the real percolation threshold for these new types of loading via variation of the concentration of CNTs as well as using second conductive filler for improvement of contacts between individual highly oriented carbon nanotubes.

\section{Conclusions}

The main goal of this study was to investigate the possibility for preparation of conductive two-component polymer blends loaded with conductive filler (CNTs in the present case) only at the interface between the two immiscible polymers. As a reference, blends with MFC structure were used and as carrier for CNTs a compatibilizer was applied. The conductivity of such blends was compared with microfibril loaded MFCs and bulk loaded homopolymers. The dispersion of CNTs in the minor component or in the interface only allows us to avoid significantly the detrimental effect of CNTs on the mechanical properties of polymers and their blends. Exploring the strong dependence of conductivity on filler concentration, experiments with compatibilizer containing higher CNT loadings are in progress with the target to determine the real threshold concentration for this type of loading. 


\section{Acknowledgements}

The authors would like to thank the Foundation for Research Science and Technology of New Zealand for the financial support (Grant No. UOAX 0406). S.F. acknowledges the financial support of the Alexander von Humboldt Foundation, Germany, in the frame of the program 'Reinvitation of former AVH awardees' making possible his stay at the Leibniz Institute of Polymer Research Dresden (IPF), where this paper was initiated. We thank Mr. Bernd Kretzschmar (IPF) for compounding the PP-g-MA/CNT compatibilizer.

\section{References}

[1] Smith J., Connell J., Delozier D. M., Lillehei P. T., Watson K. A., Lin Y., Zhou B., Sun Y-P.: Space durable polymer/carbon nanotube films for electrostatic charge mitigation. Polymer, 45, 825-836 (2004).

DOI: $10.1016 /$ j.polymer.2003.11.024

[2] Xu N. S., Wu Z. S., Deng S. Z., Chen J.: High-voltage triode flat-panel display using field-emission nanotube-based thin films. Journal of Vacuum Science and Technology B, 19, 1370-1372 (2001). DOI: $10.1116 / 1.1387451$

[3] Wang Q. H., Setlur A. A., Lauerhaas J. M., Dai J. Y., Seelig E. W., Chang R. P. H.: A nanotube-based fieldemission flat panel display. Applied Physics Letters, 72, 2912-2913 (1998). DOI: $10.1063 / 1.121493$

[4] Villmow T., Pegel S., John A., Rentenberger R., Pötschke P.: Liquid sensing: Smart polymer/CNT composites. Materials Today, 14, 340-345 (2011).

DOI: 10.1016/S1369-7021(11)70164-X

[5] Tai X., Wu G., Tominaga Y., Asai S., Sumita M.: An approach to one-dimensional conductive polymer composites. Journal of Polymer Science Part B: Polymer Physics, 43, 184-189 (2005).

DOI: $10.1002 /$ polb.20305

[6] Yoshio M., Kagata T., Hoshino K., Mukai T., Ohno H., Kato T.: One-dimensional ion-conductive polymer films: Alignment and fixation of ionic channels formed by self-organization of polymerizable columnar liquid crystals. Journal of the American Chemical Society, 128, 5570-5577 (2006).

DOI: $10.1021 / \mathrm{ja} 0606935$

[7] Lanticse L. J., Tanabe Y., Matsui K., Kaburagi Y., Suda K., Hoteida M., Endo M., Yasuda E.: Shear-induced preferential alignment of carbon nanotubes resulted in anisotropic electrical conductivity of polymer composites. Carbon, 44, 3078-3086 (2006).

DOI: $10.1016 /$ j.carbon.2006.05.008

[8] Breuer O., Sundararaj U.: Big returns from small fibers: A review of polymer/carbon nanotube composites. Polymer Composites, 25, 630-645 (2004).

DOI: $\underline{10.1002 / p c .20058}$
[9] Grossiord N., Loos J., Regev O., Koning C. E.: Toolbox for dispersing carbon nanotubes into polymers to get conductive nanocomposites. Chemistry of Materials, 18, 1089-1099 (2006).

DOI: $10.1021 / \mathrm{cm} 051881 \mathrm{~h}$

[10] Pötschke P., Bhattacharyya A. R., Janke A., Pegel S., Leonhardt A., Täschner C., Ritschel M., Roth S., Hornbostel B., Cech J.: Melt mixing as method to disperse carbon nanotubes into thermoplastic polymers. Fullerenes, Nanotubes and Carbon Nanostructures, 13, 211-224 (2005). DOI: $10.1081 /$ FST-200039267

[11] Xu X-B., Li Z-M., Yang M-B., Jiang S., Huang R.: The role of the surface microstructure of the microfibrils in an electrically conductive microfibrillar carbon black/poly(ethylene terephthalate)/polyethylene composite. Carbon, 43, 1479-1487 (2005). DOI: $10.1016 /$ j.carbon.2005.01.039

[12] Pötschke P., Bhattacharyya A. R., Janke A.: Carbon nanotube-filled polycarbonate composites produced by melt mixing and their use in blends with polyethylene. Carbon, 42, 965-969 (2004). DOI: $10.1016 /$ j.carbon.2003.12.001

[13] Gubbels F., Blacher S., Vanlathem E., Jérôme R., Deltour R., Brouers F., Teyssie P.: Design of electrical composites: Determining the role of the morphology on the electrical properties of carbon black filled polymer blends. Macromolecules, 28, 1559-1566 (1995). DOI: $10.1021 / \mathrm{ma} 00109 \mathrm{a} 030$

[14] Balberg I.: A comprehensive picture of the electrical phenomena in carbon black-polymer composites. Carbon, 40, 139-143 (2002).

DOI: $10.1016 / \mathrm{S} 0008-6223(01) 00164-6$

[15] Dong X. M., Fu R. W., Zhang M. Q., Zhang B., Rong M. Z.: Electrical resistance response of carbon black filled amorphous polymer composite sensors to organic vapors at low vapor concentrations. Carbon, 42, 25512559 (2004).

DOI: $10.1016 /$ j.carbon.2004.05.034

[16] Naficy S. Garmabi H.: Study of the effective parameters on mechanical and electrical properties of carbon black filled PP/PA6 microfibrillar composites. Composites Science and Technology, 67, 3233-3241 (2007). DOI: 10.1016/j.compscitech.2007.04.001

[17] Zhang C., Ma C-A., Wang P., Sumita M.: Temperature dependence of electrical resistivity for carbon black filled ultra-high molecular weight polyethylene composites prepared by hot compaction. Carbon, 43, 25442553 (2005).

DOI: $10.1016 /$ j.carbon.2005.05.006

[18] Hindermann-Bischoff M., Ehrburger-Dolle F.: Electrical conductivity of carbon black-polyethylene composites: Experimental evidence of the change of cluster connectivity in the PTC effect. Carbon, 39, 375-382 (2001).

DOI: $10.1016 / \mathrm{S} 0008-6223(00) 00130-5$ 
[19] Dai K., Xu X-B., Li Z-M.: Electrically conductive carbon black (CB) filled in situ microfibrillar poly(ethylene terephthalate) (PET)/polyethylene (PE) composite with a selective CB distribution. Polymer, 48, 849-859 (2007).

DOI: 10.1016/j.polymer.2006.12.026

[20] Kim Y. J., Shin T. S., Choi H. D., Kwon J. H., Chung YC., Yoon H. G.: Electrical conductivity of chemically modified multiwalled carbon nanotube/epoxy composites. Carbon, 43, 23-30 (2005).

DOI: $10.1016 /$ j.carbon.2004.08.015

[21] Bauhofer W., Kovacs J. Z.: A review and analysis of electrical percolation in carbon nanotube polymer composites. Composites Science and Technology, 69, 14861498 (2009).

DOI: 10.1016/j.compscitech.2008.06.018

[22] Byrne M. T., Gun'ko Y. K.: Recent advances in research on carbon nanotube-polymer composites. Advanced Materials, 22, 1672-1688 (2010).

DOI: $10.1002 /$ adma.200901545

[23] Spitalsky Z., Tasis D., Papagelis K., Galiotis C.: Carbon nanotube-polymer composites: Chemistry, processing, mechanical and electrical properties. Progress in Polymer Science, 35, 357-401 (2010).

DOI: 10.1016/j.progpolymsci.2009.09.003

[24] Logakis E., Pandis C., Pissis P., Pionteck J., Pötschke P.: Highly conducting poly(methyl methacrylate)/carbon nanotubes composites: Investigation on their thermal, dynamic-mechanical, electrical and dielectric properties. Composites Science and Technology, 71, 854862 (2011).

DOI: $10.1016 /$ j.compscitech.2011.01.029

[25] Fournier J., Boiteux G., Seytre G., Marichy G.: Positive temperature coefficient effect in carbon black/ epoxy polymer composites. Journal of Materials Science Letters, 16, 1677-1679 (1997).

DOI: 10.1023/A:1018582216002

[26] Bin Y., Xu C., Zhu D., Matsuo M.: Electrical properties of polyethylene and carbon black particle blends prepared by gelation/crystallization from solution. Carbon, 40, 195-199 (2002).

DOI: 10.1016/S0008-6223(01)00173-7

[27] Xiong C., Zhou Z., Xu W., Hu H., Zhang Y., Dong L.: Polyurethane/carbon black composites with high positive temperature coefficient and low critical transformation temperature. Carbon, 43, 1778-1814 (2005). DOI: 10.1016/j.carbon.2005.02.001

[28] Thongruang W., Spontak R. J., Balik C. M.: Bridged double percolation in conductive polymer composites: An electrical conductivity, morphology and mechanical property study. Polymer, 43, 3717-3725 (2002). DOI: 10.1016/S0032-3861(02)00180-5

[29] Sumita M., Sakata K., Hayakawa Y., Asai S., Miyasaka K., Tanemura M.: Double percolation effect on the electrical conductivity of conductive particles filled polymer blends. Colloid and Polymer Science, 270, 134-139 (1992).

DOI: $\underline{10.1007 / \mathrm{bf} 00652179}$
[30] Zhang L., Wan C., Zhang Y.: Morphology and electrical properties of polyamide 6/polypropylene/multiwalled carbon nanotubes composites. Composites Science and Technology, 69, 2212-2217 (2009).

DOI: 10.1016/j.compscitech.2009.06.005

[31] Pötschke P., Bhattacharyya A. R., Janke A.: Morphology and electrical resistivity of melt mixed blends of polyethylene and carbon nanotube filled polycarbonate. Polymer, 44, 8061-8069 (2003).

DOI: $10.1016 /$ j.polymer.2003.10.003

[32] Meincke O., Kaempfer D., Weickmann H., Friedrich C., Vathauer M., Warth H.: Mechanical properties and electrical conductivity of carbon-nanotube filled polyamide- 6 and its blends with acrylonitrile/butadiene/ styrene. Polymer, 45, 739-748 (2004).

DOI: $10.1016 /$ j.polymer.2003.12.013

[33] Göldel A., Kasaliwal G., Pötschke P.: Selective localization and migration of multiwalled carbon nanotubes in blends of polycarbonate and poly(styrene-acrylonitrile). Macromolecular Rapid Communications, 30, 423-429 (2008).

DOI: $10.1002 / \mathrm{marc} .200800549$

[34] Gültner M., Göldel A., Pötschke P.: Tuning the localization of functionalized MWCNTs in SAN/PC blends by a reactive component. Composites Science and Technology, 72, 41-48 (2011). DOI: 10.1016/j.compscitech.2011.09.013

[35] Goldel A., Marmur A., Kasaliwal G. R., Potschke P., Heinrich G.: Shape-dependent localization of carbon nanotubes and carbon black in an immiscible polymer blend during melt mixing. Macromolecules, 44, 60946102 (2011). DOI: $10.1021 / \mathrm{ma} 200793 \mathrm{a}$

[36] Fakirov S., Bhattacharyya D., Lin R. J. T., Fuchs C., Friedrich K.: Contribution of coalescence to microfibril formation in polymer blends during cold drawing. Journal of Macromolecular Science Part B: Physics, 46, 183-194 (2007). DOI: $10.1080 / 00222340601044375$

[37] Fakirov S., Evstatiev M.: Microfibrillar reinforced composites - New materials from polymer blends. Advanced Materials, 6, 395-398 (1994).

DOI: 10.1002/adma.19940060513

[38] Fakirov S., Evstatiev M., Petrovich S.: Microfibrillar reinforced composites from binary and ternary blends of polyesters and nylon 6. Macromolecules, 26, 52195226 (1993).

DOI: $10.1021 / \mathrm{ma} 00071 \mathrm{a} 038$

[39] Shields R. J., Bhattacharyya D., Fakirov S.: Fibrillar polymer-polymer composites: Morphology, properties and applications. Journal of Materials Science, 43, 6758-6770 (2008).

DOI: $10.1007 / \mathrm{s} 10853-008-2693-\mathrm{Z}$

[40] Lin R. J. T., Bhattacharyya D., Fakirov S.: Innovative manufacturing of carbon nanotube-loaded fibrillar polymer composites. International Journal of Modern Physics B, 24, 2459-2465 (2010). DOI: $10.1142 / \mathrm{S} 021797921006509 \mathrm{X}$ 
[41] Xu H-P., Dang Z-M., Shi D-H., Bai J-B.: Remarkable selective localization of modified nanoscaled carbon black and positive temperature coefficient effect in binary-polymer matrix composites. Journal of Materials Chemistry, 18, 2685-2690 (2008).

DOI: $10.1039 / \mathrm{B} 717591 \mathrm{D}$

[42] Gao J-F., Yan D-X., Yuan B., Huang H-D., Li Z-M.: Large-scale fabrication and electrical properties of an anisotropic conductive polymer composite utilizing preferable location of carbon nanotubes in a polymer blend. Composites Science and Technology, 70, 19731979 (2010).

DOI: 10.1016/j.compscitech.2010.07.019

[43] Zhang Y-C., Dai K., Tang J-H., Ji X., Li Z-M.: Anisotropically conductive polymer composites with a selective distribution of carbon black in an in situ microfibrillar reinforced blend. Materials Letters, 64, 1430-1432 (2010).

DOI: $10.1016 /$ j.matlet.2010.03.041

[44] Li Z-M., Xu X-B., Lu A., Shen K-Z., Huang R., Yang M-B.: Carbon black/poly(ethylene terephthalate)/polyethylene composite with electrically conductive in situ microfiber network. Carbon, 42, 428-432 (2004).

DOI: $10.1016 /$ j.carbon.2003.10.032

[45] Dai K., Li Z-M., Xu X-B.: Electrically conductive in situ microfibrillar composite with a selective carbon black distribution: An unusual resistivity-temperature behavior upon cooling. Polymer, 49, 1037-1048 (2008). DOI: 10.1016/j.polymer.2007.12.043

[46] Shaffer M. S. P., Windle A. H.: Fabrication and characterization of carbon nanotube/poly(vinyl alcohol) composites. Advanced Materials, 11, 937-941 (1999). DOI: 10.1002/(sici)1521-4095(199908)11:11<937::aidadma937>3.0.co;2-9

[47] Evstatiev M., Fakirov S., Friedrich K.: Manufacturing and characterization of microfibrillar reinforced composites from polymer blends. in 'Polymer composites' (eds.: Friedrich K., Fakirov S., Zhang Z.) 149-167 (2005).

[48] Fakirov S.: Modified Soxhlet apparatus for high-temperature extraction. Journal of Applied Polymer Science, 102, 2013-2014 (2006).

DOI: 10.1002/app.23397
[49] Menzer K., Krause B., Boldt R., Kretzschmar B., Weidisch R., Pötschke P.: Percolation behaviour of multiwalled carbon nanotubes of altered length and primary agglomerate morphology in melt mixed isotactic polypropylene-based composites. Composites Science and Technology, 71, 1936-1943 (2011).

DOI: 10.1016/j.compscitech.2011.09.009

[50] ANSI/ESD S541-2008: Packaging material standards for ESD sensitive items (2008).

[51] Pötschke P., Andres T., Villmow T., Pegel S., Brünig H., Kobashi K., Fischer D., Häussler L.: Liquid sensing properties of fibres prepared by melt spinning from poly(lactic acid) containing multi-walled carbon nanotubes. Composites Science and Technology, 70, 343349 (2010). DOI: $10.1016 /$ j.compscitech.2009.11.005

[52] Seo M-K., Park S-J.: Electrical resistivity and rheological behaviors of carbon nanotubes-filled polypropylene composites. Chemical Physics Letters, 395, 4448 (2004).

DOI: $10.1016 /$ j.cplett.2004.07.047

[53] Logakis E., Pissis P., Pospiech D., Korwitz A., Krause B., Reuter U., Pötschke P.: Low electrical percolation threshold in poly(ethylene terephthalate)/multi-walled carbon nanotube nanocomposites. European Polymer Journal, 46, 928-936 (2010). DOI: $10.1016 /$ j.eurpolymj.2010.01.023

[54] King J. A., Via M. D., King M. E., Miskioglu I., Bogucki G. R.: Electrical and thermal conductivity and tensile and flexural properties: Comparison of carbon black/polycarbonate and carbon nanotube/polycarbonate resins. Journal of Applied Polymer Science, 121, 2273-2281 (2011).

DOI: $10.1002 / a p p .33890$

[55] Pötschke P., Bhattacharyya A. R., Janke A., Goering H.: Melt mixing of polycarbonate/multi-wall carbon nanotube composites. Composite Interfaces, 10, 389404 (2003). DOI: $10.1163 / 156855403771953650$ 